\title{
The Role of Soluble, Insoluble Fibers and Their Bioactive Compounds in Cancer: A Mini Review
}

\author{
Dimitrios Papandreou, Zujaja Tul Noor, Maitha Rashed \\ Department of Natural Sciences \& Public Health, CSSH, Zayed University, Abu Dhabi, UAE \\ Email: papandreoudimitrios@yahoo.gr
}

Received 23 October 2014; revised 30 November 2014; accepted 16 December 2014

Copyright (C) 2015 by authors and Scientific Research Publishing Inc.

This work is licensed under the Creative Commons Attribution International License (CC BY). http://creativecommons.org/licenses/by/4.0/

C) (i) Open Access

\begin{abstract}
The cancer incidence has risen dramatically over the last decades. About 8 million people died globally according to latest reports, which represented almost $40 \%$ more than it was 20 years ago. Risk factors for the development of cancer have been found to include smoking, alcohol, drugs, obesity and diet. Fiber intake has shown to exhibit chemoprotective effects on cancer proliferation and metastasis that may seem to be very promising. This article will review the role of different types of fiber such as, cellulose, lignin, pectin and inulin in development and prevention of different types of cancers. This article would also discuss the effectiveness of both types of fiber in cancer prevention.
\end{abstract}

\section{Keywords}

Fiber, Cancer, Insoluble, Soluble, Bioactive Compounds

\section{Introduction}

Cancer holds a significant burden in world disease prevalence. As in 2010, there were 52.8 million deaths globally of which 8 million people died from cancer, which was 38\% more than two decades ago [1]. According to the global statistical report of 2011, the four major cancer sites in male adults are lung, prostate, colon \& rectum and stomach, while in female adults these are breast, colon \& rectum, cervix and stomach; however, esophageal, ovary and liver cancers are on the top of the list [2]. Moreover, the incidence and mortality for these cancers are higher in developed countries than in developing countries (this variation could be due to disparate set of risk factors and diagnostic practices) [3]. A total of 1,665,540 new cancer cases and 585,720 cancer deaths are projected to occur in the United States in 2014 [3]. The incidence and mortality for the four most common types of 
cancer, which are: colorectal cancer, breast cancer, prostate cancer and stomach cancer are highest in Australia/ New Zealand, Western Europe, Australia/New Zealand and Eastern Asia for incidence cases respectively [2]. And, the mortality due to these cancers is highest in Australia/New Zealand, Southern Africa, Caribbean and Eastern Asia respective to the cancer types mentioned before; however, these statistics could vary due to different diagnostic conditions in developed, developing and under-developed countries [2].

Another important factor for disparity in incidence and mortality could be due to availability of preventive measure and treatments, such as, drugs for cancer. INTCR reported inequality in cancer drugs sale, as cancer burden in US was around 20\%, but the drug availability was around 60\%; in Japan burden was around 20\%, and drug was available to almost 5\%; in Europe burden was 20\% with availability of drug slightly less than 20\%; however rest of the world faced around $60 \%$ of cancer burden with only $5 \%$ drug accessibility [4]. Cancer is linked to many environmental factors, such as, smoking, alcohol, obesity, and diet, but this article would concentrate on specific dietary substances such as "fiber" that has been found to induce a chemopreventive role on cancer proliferation and metastasis [5]. This article would address how the epigenetics (environment related effect) on the genes lead to cancer. Furthermore, we would try to define the different types of fiber, how they act as functional foods, and the mechanism that dietary fiber follows to increase apoptosis of cancer cells, and reduce tumorgenesis. In the end, we will analyze the two biologically active families of insoluble fiber and soluble fiber, cellulose, lignin, and pectin, inulin, respectively. Dietary fiber effectiveness is an ongoing debate. Studies identified in this article mainly support the functional efficacy of this polysaccharide; however there are few studies that do not support all types of fiber in their success against some forms of cancers.

\section{Etiology of Cancer, and Diet as an Epigenetic Factor}

Cancer is a heterogeneous disease; the pathology of this disease is linked to genetic (genes), cytogenetic (chromosomes), and epigenetic (gene-environment) alterations [6]. Tumor is a general term used to describe abnormal growth of cell, but when these cells continue to destruct other tissues around them, they are called cancer. Cancer cells could spread around the body, defined as metastasis. Individual susceptibility to cancer is determined through interaction between genes and environment. Even with similar exposures to risk factors or amongst twins [7], cancer from origin to proliferation to recovery is linked to the genomic stability [8], somatic mutation and epigenetic factors that occur randomly [9] in all individuals. Cancer due to epigenetics is described by aberrations in the following four mechanisms; range of post-translational modifications to modify histones (protein around which genetic material coils), DNA methylation, chromatin remodeling and non-coding RNAs [6] [8]. The lack of precise biomarkers [6] [7], need for advanced imaging technique [10] [11], statistical techniques limitations, and hypothesized loci on DNA with limited work on them [12]-[14]; are some factors that currently prevent exploration of root to cancer, and therefore to analyze risk and prevent the disease. A significant element, under the umbrella of gene-environment interaction/epigenetics, is diet [5]; therefore, the National Institutes of Health $(\mathrm{NIH})$ recommends a high fiber, low fat diet, with abundant intake of fruits and vegetables for cancer prevention [15]. Studies to-date suggests significantly inverse (positive) as well as equivocal relationship [16] between diet and some cancer. For instance, a study carried out in 2011 indicate minimal gene-environment interaction, as there is not convincing association between fruits, vegetables consumption and risk of Colorectal Cancer (CRC), and only marginally significant relationship with red meat and calcium [17]. Whereas, another study carried out in 2012 indicated effectiveness of vegetable only [12]. Later, another study in 2014 with efforts employed to improve statistical analysis, reflected gene-environment interaction for meat at genome-wide significance threshold in increasing cancer, and for fiber, fruits and vegetables in decreasing cancer [13] [18]. There is no set RDA (Recommended Dietary Allowance) for fiber consumption, but the adequate intake (AI) for age group 1 - 3 is $19 \mathrm{~g}$, for age group 4 - 8 is $25 \mathrm{~g}$, age group 9 - 13 is $31 \mathrm{~g}$ for male and $26 \mathrm{~g}$ for female; age groups 14 - 50 is set at $38 \mathrm{~g}$ for males and $25 \mathrm{~g}$ for females, adults over 50 years have AI of $30 \mathrm{~g}$ for male and $21 \mathrm{~g}$ for females, pregnant women set limits are $28 \mathrm{~g}$ and $29 \mathrm{~g}$ for lactating women [19]. Vegetarians routinely consume 40 to $50 \mathrm{~g}$ dietary fiber daily without any side effects, but still there is no limit set for upper intake level [20]. Fiber supplements may also be appropriate for some patients, but the type of the fiber should be known and be appropriate for the different type of cancer being treated [20].

\section{Introduction to Different Types of Dietary Fiber, and Associations with Some Forms of Cancer}

Dietary Fiber gained significance as an important nutritional concept in 1960s and 1970s when researchers noted 
differences in diseases in Europe (high) and Africa (comparatively lower), which they associated with diet [21]. The diseases that were linked with fiber in 1970 were constipation, diverticular disease, hiatal hernia, appendicitis, varicose veins, piles (hemorrhoids), gallstones, obesity, cancer of the large intestine, coronary heart disease, diabetes type 2, but now many dietary fibers have also shown chemoprotective effect for many different types of cancers [22]-[27].

Dietary fiber is further categorized into soluble fiber, and insoluble fiber, on the basis of their dissolution capability in water, ease of digestion by floral bacteria in intestine and other chemical properties; such as, water retention [28]. In insoluble fiber, carbohydrate chain does not dissolve in water, fermentation is limited, they retain water. Soluble fiber forms a gel like substance delaying the gastric emptying, and also retains water. Papas et al. [29] describe different sources of fiber, as it is stated that "a moderate to high proportion of fruit fiber from commonly consumed fruits is soluble fiber (largely pectin). Oats (largely gums), legumes (largely gums), and some vegetables (largely pectin), including carrots, cabbage, Brussels sprouts, squash, and broccoli, also contain higher proportions of soluble fiber, whereas wheat bran fiber primarily consists of insoluble fiber" [29]. Fiber can also bind to potential nutrients and nutrient precursors preventing their absorption, sometimes possibly harmful substances too; such as, bile acid [28]. Dietary fibers are fermented in the GI tract leading to the generation of various bioactive materials, for example, short-chain fatty acids (SCFAs), which could provide defense against cancer by increasing apoptosis [28]. Dietary fiber can be separated into many different fractions/families. These fractions include arabinoxylan, inulin, lignin, psyllium, pectin, bran, cellulose, $\beta$-glucan and resistant starch, guar gum [28]. Pathways of how different types of fiber effect cancerous cells have been analyzed; some fibers have shown to reduce tumorgenesis by regulating cell growth, survival and apoptosis. Fiber increase expression of proapoptic factors, and suppresses the antiapoptic and/or cell proliferating chemicals and transcription [30] [31].

It has been concluded that insoluble fiber may provide slightly higher chemoprotection compared to soluble one [32]. In a large cohort study intakes of legumes, whole grains, and cruciferous vegetables were also associated with a $16 \%$ - $18 \%$ reduced risk of renal cell carcinoma [33]. Dietary fiber in the form of insoluble is also likely to reduce risk of nasopharyngeal carcinoma as it is found in a case-control study with sample of 792 people [33]. Dietary fiber also reduces endometrial cancer risk by $29 \%$ - $46 \%$ with sources of fiber, including cereal and vegetable and fruit fiber; moreover, soy products and legumes also reduced the endometrial cancer [34].

Dietary fibers also bind to carcinogens, bile acids, potential toxins, and essential nutrients; such as, minerals, which can inhibit the carcinogenic process, but according to study and evidence obtained, cereal fiber show negative relation [35]; as fiber decreases luminal $\mathrm{pH}$ that increases cell proliferation in colon leading to tumor enhancement [36]; whereas, vegetable fiber is linked positively, but this is attributed to the other biologically active components named earlier [35]. This study provides results contrary to the recent one, where a diet rich in dietary fiber is associated with a reduction in colon cancer risk [37], because butyrate (BT) is one of the main end products of anaerobic bacterial fermentation of dietary fiber in the human colon [38] that may affect colonic and fecal $\mathrm{pH}$ and contribute to antiproliferative activity [39].

Fiber effectively influences digestive tract, and may enhance energy excretion; this property is beneficial, as caloric intake has been correlated positively with cancer risk [39]. This proves the statement in introduction that the results of studies in fiber are equivocal, because there are conflicting evidences for effects of dietary fiber role in cancer protection [40]. One of the other ways dietary fibers may protect against colorectal cancer is by adsorbing carcinogens and carrying them out of the digestive tract, thus lessening interaction of the carcinogens with the colonic tissue [41]; for instance, fiber enhances de-conjugation of bile acids [42]. Bile acids (BA) are normal components of the luminal contents of the gastrointestinal (GI) tract, where they enable absorption of lipids, cholesterol, and fat-soluble vitamins [43]. Dietary fiber also promotes microflora that has definite effects on the human host in cholesterol metabolism as it binds to cholesterol and increases its fecal volume, improves glucose tolerance by not allowing sudden rise in serum glucose level, therefore, it may explain such diseases as carcinoma [44] [45] since the anti-hyperglycemic character is protective in this cases, because insulin is a growth factor that influences proliferation and apoptosis [29].

\section{Insoluble Fiber; Cellulose Role in Cancer Development, Mechanism and Epidemiological Studies}

Cellulose is an insoluble fiber, beneficial for it aids the intestines to perform digestion efficiently. Similar to 
general characteristic of fiber, cellulose also bind to other micronutrients, and toxins such as, bile acids. Bile acids association with cancer has been proven, due to its damaging impact on DNA, and now studies also suggest bile acids link with cellulose, where cellulose in a role of "catalyst", stimulates "polyesterification" of bile acid, and turns it to an "inactive form" reducing the fecal toxicity [46]. A report on concentration of secondary fecal bile including 15 healthy individuals concluded that wheat and rye fiber (rich in cellulose) lead to low concentration in the fecal bile [46]. High bile acid concentration can also lead to colon cancer, it was considered in "carcinogens" in 1939, and the most dominant cause was fat intake, since it was prevalent among individuals who have a high dietary fat intake [47]. Evidence has been showed to prove the mechanism of secondary bile acids effect leading to colon cancer [47]. Their amphipathic nature enables them to get involved in emulsification and digestion of dietary fats; yet, levels above those that are physiologic are potentially membrane damaging [48]. Bile Acids can induce genomic instability in colonic epithelial cells through multiple mechanisms, including the disruption of mitosis (leading to aneuploidy), defects in spindle assembly checkpoints, oxidative DNA damage, cell cycle arrest at G1 and/or G2 along with improper alignment of chromosomes at the metaphase plate and multipolar divisions [49]. A study by Sloan et al. also indicated colon cancer prevention due to cellulose [50]. Sixty Sprague-Dawley rats were pair-fed one of three nutritionally identical diets, low and high in fiber, composed of either cellulose or lignin [50]. Although both "high fiber" diets had similar stool bulking effects, only the cellulose diet was associated with a reduction in 1,2-dimethylhydrazine (DMH)-induced colon neoplasms [50]. The cellulose diet was also associated with distinct changes in the gut bacterial profile and with a lowered serum cholesterol [50]. Protection in stomach cancer cases from cellulose is also notable [22]. In a study the result obtained for stomach cancer provided with cellulose showed a significant protective effect [22]. Other studies showed protective effect of fiber consumption, especially from vegetables, in regards with ovarian cancer, and when fibers was classified according to the source, it showed comparatively more significant protective effect of cellulose [51]. In another study cellulose provided moderate protection from breast cancer, especially in pre-menopausal women [52], whereas, another study indicated a very strong protective role of cellulose (OR 0.04; 95\% CI 0.01 - 0.31) in post-menopausal women, especially when fiber intake was from fruits and vegetables [5]. Additionally, researches have also indicated reduced risk of laryngeal [26], esophageal cancer [24], oral and pharyngeal [27], with significantly low odds ratio, as it was reported in a similar study in Italy indicated odds ratio of 0.37 for soluble fiber, 0.52 for cellulose, 0.48 for other insoluble fiber [27], respectively. The role of fiber in renal cell carcinoma has been also investigated and suggested a strong protective effect odds ratio of 0.37 (95\% CI: 0.22 - 0.64) for cellulose. In a similar study in the past the results showed only a modest positive effect [22]. The study on cellulose is an ongoing process, and with the results of studies stated afore, it can be understood that cellulose, found in fruits, vegetables, whole grains and rye all provide strong protection from various common cancers.

\section{Insoluble Fiber; Lignin Role in Cancer Development, Mechanism and Epidemiological Studies}

Lignin, another form of insoluble fiber, contains many different chemical species, including ferulic acid, coumaric acid, vanillic acid, vanillin, syringaldehyde and furfural [53]. From the perspective of biofuels, these compounds are problematic, and can cause downstream loss of product if not removed prior to beginning the fermentative process [53]. In contrast, the same compounds have beneficial properties pertaining to human health, including their role as antioxidants and in cancer prevention, or sometimes their involvement in bacterial cell-to-cell signaling [53]. Lignin is one of the major components of dietary fiber. It is a complex hydrophobic molecule that typically occurs in cell walls with heteroxylans [54]. Cell walls that contained lignin or suberin adsorbed hydrophobic carcinogens particularly well; furthermore, the presence of lignin, and probably suberin, in the walls makes them resistant to degradation in the colon [55]. Experimental studies in animals treated with carcinogens suggested that some fibers may exert protective effects in the intestines and others may enhance colon carcinogenesis [56]. The incidence and multiplicity of small intestinal tumors as well as the number of colon adenocarcinomas per tumor-bearing animal were lower in animals fed the lignin diet than in those fed the control diet. Bile acids act as promoters of colonic tumors in mutagenesis assay systems and also in various animal models [57]. Lignin in this case increases the fecal excretion of these steroids and bile acids, which in turn affects hormone metabolism and cell growth [58]. Lignin had no effect on the concentrations of fecal bile acids, but the daily output of total bile acids was increased in animals fed the lignin diet as compared to the daily out- 
put in rats fed the control diet [59]. Moreover, due to their "radical-scavenging” activity they reduce colon cancer [54]. Western diet is linked to breast cancer, prostate cancer, coronary heart disease, and colon cancer; which lead to elevation in levels of sex hormones, with decreased SHBG and bioavailability of these hormones [58]. Phytoestrogens have been suggested to have a protective effect on hormone-sensitive cancers [53]. Estrogenic substances present in various lignin foods sources are associated with postmenopausal breast cancer risk too [60]. Lignin, due to its phytoestrogenic effect, is shown to prevent estrogen related cancer; such as, breast cancer, prostate cancer [60] and endometrial cancer [34]. This is explained by some of the ingested plant lignans, which are converted by intestinal microbiota to enterolignans, enterodiol (END) and enterolactone (ENL), which has been thought to be the major biologically active lignan, and suggested to be associated with low risk of mammary cancer [61] [62]. Flaxseed (FS), rich in the phytoestrogen, $\alpha$-linolenic acid, and oil of lignin; secoisolariciresinoldiglucoside (SDG), which after ingestion, is converted to secoisolariciresinol that is further metabolised to the mammalian lignansenterodiol and enterolactone provide indirect protection against cancer [62]. Mechanism to this positive property was provided by human and animal studies that identify SDG metabolites possible protection against CVD and the metabolic syndrome by reducing lipid and glucose concentrations, lowering blood pressure, and decreasing oxidative stress and inflammation [54]. Lignans achieve this anticarcinogenic property by binding to Type II estrogen-binding sites, and probably inhibit cell growth and proliferation of hormone-dependent growth [60] [63]. Another important effect of lignin is its stimulation capacity of SHBG (sex hormone binding globulin) synthesis in liver [60]. Mechanisms for hormone related cancers include decreased cell proliferation and angiogenesis and increased apoptosis through modulation of estrogen metabolism and estrogen receptor and growth factor receptor signaling pathways [60]. Lignin also reduces the thyroid cancer risk, but it needs further research [64]. Therefore, lignin capacity to act as antioxidant and phytoestrogen provide them anticarcinogenic properties against many cancers.

\section{Soluble Fiber; Pectin Role in Cancer Development, Mechanism and Epidemiological Studies}

Pectin is family of complex polysaccharide possessing anti-tumorgenesis properties, especially in modified forms, as the different chains that compose this soluble fiber suppress expression of tumor facilitators [65]. Pectin, as dietary fiber, $\mathrm{pH}$ modified, and modified chain has been found to show anti-tumor activity [65]. Pectin is fermented in colon producing short fatty acid chains; such as, acetate, propionate and butyrate, these fiber chains also bind to other minerals and bile acid, eliminating them and reducing toxicity [66]. Pectin helps to promote pro-biotic atmosphere in intestines, owing to this characteristic studies have been carried out in past to study their effectiveness in cancer prevention. Pectin acid is effective in treatments of pituitary tumors, as they increased cell death and DNA damage i.e. apoptosis, also promoting necrosis if the diet pectin acid diet administered was 2.5 and $5 \mathrm{mg} /$ day in rats without any toxic effects; therefore, it is suggested as a chemoprotective technique to replace bromocriptine drug that shows same anti-tumor effectiveness [67]. Another recommended combination with chemoprotective effect from colon cancer is fish oil/pectin diet. According to numerous studies, a comparison was made between fish oil/pectin and corn oil/cellulose, where highly fermentable pectin and eicosapentanoic acid and docosahexaenoic acid had lesser colon cancer incidence with higher occurrence apoptic cells [30] [68]. The mechanism is explained through the epigenetic effect of diet. Pectin has also shown protective effects against cancer in its modified form (Modified Citrus Pectin/MCP). Heat-treated Pectin reduces cancerous activity by inducing apoptosis, and arresting the cells at G2/M phase (the growth of cell was reduced by $49 \%$ compared to control group) [69]. The pectin containing diets were more effective in enhancing the transcription factors that inhibit tumor cell growth, and suppressing expression of factors that protect colonocytes from apoptosis [70]. Pectin also holds the ability to bind to Galectin-3, a pro-metastatic regulatory protein, that inhibits apoptosis, promotes cell growth and regulates $\mathrm{T}$-cell receptor signal transduction (T-cells that recognize the antigens, in this case these are tumor antigens) [71]. A study involving mices, has also indicated modified pectin capability to reduce mammary and colon tumor growth and metastasis by inhibiting angiogenesis, as the researchers state that "metastases to lymph nodes and the liver were present in $100 \%$ and $66 \%$ of control mice versus $25 \%$ and $0 \%$ of mice fed with MCP” mainly by binding and inhibiting Galectin-3 function cell proliferation and angiogenesis (formation of new blood cells from old vessles) [72]. A component of pectin i.e. butyrate has shown to inhibit migration and invasion potential of tumor cells by increasing G1 and G2 phase, with drop in S phase of cell cycle [73]. Niacin and butyrate also activate a G-protein-coupled receptor whose expression in 
human breast could decrease cyclic-AMP production, induce apoptosis and block colony formation, providing anti-tumorgenesis character [74]. Citrus Pectin effectiveness against colonization by melanoma [75] tumor cells have been shown too, probably because citrus pectin binds to tumor ligands i.e. anti-adhesive property, thus affecting cellular interactions for metastasis and emoli of tumor cells [76]. Injection of MCP significantly decreased experimental metastasis (greater than 90\%) [76]. Modified citrus pectin mechanism of action is mainly linked to binding with Galectin-3 protein, the ability to inhibit tumor cell adhesion and chemotaxis. Pectin as an epigenetic factor show positive role especially in its modified form, and short fatty acid chains produced during fermentation, therefore, it has become a major topic of interest as drugs are now manufactured from this polysaccharide.

\section{Soluble Fiber; Inulin Role in Cancer Development, Mechanism and Epidemiological Studies}

Inulin is another dietary fiber belonging to soluble family of fructans that act as functional food. Inulin is hydrolyzed and completely fermented by colonic microflora and produce gases and short chain fatty acids. These short chain fatty acids are accompanied by production of butyrate that is shown to reduce colon carcinogenesis [77] [78], and large-bowel cancer by inducing apoptosis [79]. Inulin increases absorption of vitamins and minerals; especially calcium and magnesium, protects body from translocation of bacteria and proliferation of pathogens, regulates intestinal epithelial cell growth, contributes to immune functions, and reduces triglycedaemia in hyperlipidaemic and hyperinsulemia individuals [80]. Inulin protected the mucosal and submucosal membranes against protein oxidation, reducing the oxidative stress, by protecting colon from lipopolysaccharides (LPS)induced damage [81]. LPS are produced by gram-negative bacteria that impair intestinal smooth muscle contractibility, and increase inflammation [81]. It has been hypothesized that hyperinsulemia could be a key factor in tumor development, Inulin by decreasing serum glucose could inhibit tumor growth; moreover, the prebiotic bacteria growth complements the lactic acid, which is shown to have antigenotoxic and anticarcinogenic properties [11] [82]. Inulin is also shown to have inhibitory effect on the development of lung metastases of tumor in mice [83]. Thus, the positive effect of Inulin rose from their property of fermentation, producing and complementing the beneficial chemicals, and protecting against cancer. Table 1 gives a summary of different types of fiber used for particular cancers. At this point one can conclude, that cancer does not follow same path in every case, rather different hypothesized genes are involved that still require investigation, and even the different sources and family of dietary fibers could influence the protective effect against it.

Table 1. Effects of different types of fibers in various cancers.

\begin{tabular}{|c|c|c|c|c|c|}
\hline & & \multicolumn{2}{|c|}{ Insoluble fiber } & \multicolumn{2}{|c|}{ Soluble fiber } \\
\hline \multirow{13}{*}{ 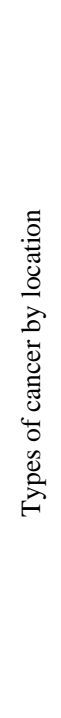 } & & $\underline{\text { Cellulose }}$ & $\underline{\text { Lignin }}$ & $\underline{\text { Pectin }}$ & $\underline{\text { Inulin }}$ \\
\hline & Colon & $\mathrm{D}[47][50]$ & $\mathrm{D}[54][57]$ & $\mathrm{D}[36][38][70][72]$ & $\mathrm{D}[77][78]$ \\
\hline & Intestinal & NDR & $\mathrm{D}[57]$ & NDR & $\mathrm{D}[79][81]$ \\
\hline & Stomach & $\mathrm{D}[22]$ & NDR & NDR & NDR \\
\hline & Ovarian & $\mathrm{D}[51]$ & NDR & NDR & NDR \\
\hline & Breast & $\mathrm{D}[52][53]$ & $\mathrm{D}[60][62]$ & $\mathrm{D}[72][74]$ & NDR \\
\hline & Prostate & NDR & $\mathrm{D}[60]$ & NDR & NDR \\
\hline & Laryngeal, oral, pharyngeal, esophagal & $\mathrm{D}[24][26][27]$ & NDR & NDR & NDR \\
\hline & Endometrial & NDR & $\mathrm{D}[34]$ & NDR & NDR \\
\hline & Renal & $\mathrm{D}[23]$ & NDR & NDR & NDR \\
\hline & Thyroid & NDR & $\mathrm{D}[64]$ & NDR & NDR \\
\hline & Pitutary & NDR & NDR & $\mathrm{D}[67]$ & NDR \\
\hline & Lung & NDR & NDR & NDR & $\mathrm{D}$ [83] \\
\hline
\end{tabular}

Abbreviations: $\mathrm{D}=$ decrease, $\mathrm{NDR}=$ no data reported. 


\section{Conclusion}

This article concludes with a positive perception regarding the beneficial effect of dietary fiber for many common forms of cancer. Since dietary fiber showed its chemoprotective property in both soluble and insoluble forms, according to studies, none of the two types of fiber and its bioactive compounds outweighed each other. Rather, we may select the type of fiber intake through diet in accordance to their medical conditions. Hence, the preference for each type of fiber may change, but we can still retain the benefits of dietary fiber in general to reduce and prevent cancer. And, as mentioned at beginning of the article, cancer holds large burden in society, especially in the developed world; thus, the health organizations need to carefully address this issue, and people should be more concerned about their daily-required intake. Fiber not only prevents cancer, but also protects from other common disease, such as, CVD and diabetes mellitus 2 . Therefore, fiber intake should be adequate and administered through diet to preserve and maintain life, even if we do not consider ourselves to be at high risk of cancer.

\section{References}

[1] Lozano, R., Naghavi, M., Foreman, K., Lim, S., Shibuya, K., Aboyans, V., et al. (2012) Global and Regional Mortality from 235 Causes of Death for 20 Age Groups in 1990 and 2010: A Systematic Analysis for the Global Burden of Disease Study 2010. Lancet, 380, 2095-2128. http://dx.doi.org/10.1016/S0140-6736(12)61728-0

[2] Jemal, A., Bray, F., Center, M.M., Ferlay, J., Ward, E. and Forman, D. (2011) Global Cancer Statistics. CA: A Cancer Journal for Clinicians, 61, 69-90. http://dx.doi.org/10.3322/caac.20107

[3] Siegel, R., Ma, J., Zou, Z. and Jemal, A. (2014) Cancer Statistics, 2014. CA: A Cancer Journal for Clinicians, 64, 9-29. http://dx.doi.org/10.3322/caac.21208

[4] Orang-Ojong, B.B., Munyangaju, J.E., Wei, M.S., Lin, M., Wei, F.G., Foukuang, C. and Zhu, Y. (2013) Impact of Natural Resources and Research on Cancer Treatment and Prevention: A Perspective from Cameroon. Molecular and Clinical Oncology, 1, 610-620.

[5] Zaridze, D., Lifanova, Y., Maximovitch, D., Day, N.E. and Duffy, S.W. (1991) Diet, Alcohol Consumption and Reproductive Factors in a Case-Control Study of Breast Cancer in Moscow. International Journal of Cancer, 48, 493-501. http://dx.doi.org/10.1002/ijc.2910480404

[6] Sandoval, J. and Esteller, M. (2012) Cancer Epigenomics: Beyond Genomics. Current Opinion in Genetics and Development, 22, 50-55. http://dx.doi.org/10.1016/j.gde.2012.02.008

[7] Nystrom, M. and Mutanen, M. (2009) Diet and Epigenetics in Colon Cancer. World Journal of Gastroenterology, 15, 257-263. http://dx.doi.org/10.3748/wjg.15.257

[8] Bannister, A.J. and Kouzarides, T. (2011) Regulation of Chromatin by Histone Modifications. Cell Research, 21, 381395. http://dx.doi.org/10.1038/cr.2011.22

[9] Murrell, A., Hurd, P.J. and Wood, I.C. (2013) Epigenetic Mechanism in Development and Disease. Biochemical Society Transactions, 41, 697-699. http://dx.doi.org/10.1042/BST20130051

[10] Buas, M.F. and Vaughan, T.L. (2013) Epidemiology and Risk Factors for Gastroesophageal Junction Tumors: Understanding the Rising Incidence of This Disease. Seminars in Radiation Oncology, 23, 3-9. http://dx.doi.org/10.1016/j.semradonc.2012.09.008

[11] Geier, M.S., Butler, R.N. and Howarth, G.S. (2006) Probiotics, Prebiotics and Synbiotics: A Role in Chemoprevention for Colorectal Cancer? Cancer Biology and Therapy, 5, 1265-1269. http://dx.doi.org/10.4161/cbt.5.10.3296

[12] Hutter, C.M., Chang-Claude, J., Slattery, M., Pflugeisen, B.M., Lin, Y., Dugan, D., et al. (2012) Characterization of Gene-Environment Interactions for Colorectal Cancer Susceptibility Loci. Cancer Research, 72, 2036-2044. http://dx.doi.org/10.1158/0008-5472.CAN-11-4067

[13] Figueiredo, J.C., Hsu, L., Hutter, C.M., Lin, Y., Campbell, P.T., Baron, J.A., et al. (2014) Genome-Wide Diet-Gene Interaction Analyses for Risk of Colorectal Cancer. PLoS Genetics, 10, e1004228.

[14] Park, J.H., Wacholder, S., Gail, M.H., Peters, U., Jacobs, K.B., Chanock, S.J. and Chatterjee, N. (2010) Estimation of Effect Size Distribution from Genome-Wide Association Studies and Implications for Future Discoveries. Nature Genetics, 42, 570-575. http://dx.doi.org/10.1038/ng.610

[15] Subramaniam, D., Thombre, R., Dhar, A. and Anant, S. (2014) DNA Methyltransferases: A Novel Target for Prevention and Therapy. Frontiers in Oncology, 4, 80. http://dx.doi.org/10.3389/fonc.2014.00080

[16] Alexander, D.D. and Cushing, C.A. (2011) Red Meat and Colorectal Cancer: A Critical Summary of Prospective Epidemiologic Studies. Obesity Reviews, 12, e472-e493. http://dx.doi.org/10.1111/j.1467-789X.2010.00785.x 
[17] Figueiredo, J.C., Lewinger, J.P., Song, C., Campbell, P.T., Conti, D.V., Edlund, C.K., et al. (2011) Genotype-Environment Interactions in Microsatellite Stable/Microsatellite Instability-Low Colorectal Cancer: Results from a Genome-Wide Association Study. Cancer Epidemiology, Biomarkers and Prevention, 20, 758-766. http://dx.doi.org/10.1158/1055-9965.EPI-10-0675

[18] Koushik, A., Hunter, D.J., Spiegelman, D., Beeson, W.L., van dan Brandt, P.A., Buring, J.E., et al. (2007) Fruits, Vegetables, and Colon Risk in a Pooled Analysis of 14 Cohort Study. Journal of the National Cancer Institute, 99, 14711483. http://dx.doi.org/10.1093/jnci/djm155

[19] National Research Council (2005) Dietary Reference Intakes for Energy, Carbohydrate, Fiber, Fat, Fatty Acids, Cholesterol, Protein, and Amino Acids (Macronutrients). The National Academies Press, Washington DC.

[20] Slavin, J.L. (1987) Dietary Fiber: Classification, Chemical Analyses, and Food Sources. Journal of the American Dietetic Association, 87, 1164-1171.

[21] Burkitt, D.P. and Trowell, H.C. (1976) Refined Carbohydrate Foods and Disease-Some Implications of Dietary Fibre. Postgraduate Medical Journal, 52, 476. http://dx.doi.org/10.1136/pgmj.52.609.476-c

[22] Bravi, F., Scotti, L., Bosetti, C., Bertuccio, P., Negri, E. and La Vecchia, C. (2009) Dietary Fiber and Stomach Cancer Risk: A Case-Control Study from Italy. Cancer Causes and Control, 20, 847-853. http://dx.doi.org/10.1007/s10552-009-9309-z

[23] Galeone, C., Pelucchi, C., Talamini, R., Negri, E., Montella, M., Ramazzotti, V., et al. (2007) Fibre Intake and Renal Cell Carcinoma: A Case-Control Study from Italy. International Journal of Cancer, 121, 1869-1872. http://dx.doi.org/10.1002/ijc.22913

[24] Li, H.Q., Diao, Y.T., Li, H., Zhou, Y.Z., Yang, Y.F., Fang, X.Q., Wang, Y., Wu, K., Zhao, D.L., Zhou, R.X. and Lei, F.H. (2007) The Risk Factors Related to Esophageal Squamous Cell Cancer in Feicheng County, China. Chinese Journal of Preventive Medicine, 41, 56-61.

[25] Pelucchi, C., Talamini, R., Galeone, C., Negri, E., Franceschi, S., Dal Maso, L., et al. (2004) Fibre Intake and Prostate Cancer Risk. International Journal of Cancer, 109, 278-280. http://dx.doi.org/10.1002/ijc.11688

[26] Pelucchi, C., Talamini, R., Levi, F., Bosetti, C., La Vecchia, C., Negri, E., Parpinel, M. and Franceschi, S. (2003) Fibre Intake and Laryngeal Cancer Risk. Annals of Oncology, 14, 162-167. http://dx.doi.org/10.1093/annonc/mdg032

[27] Soler, M., Bosetti, C., Franceschi, S., Negri, E., Zambon, P., Talamini, R., Conti, E. and La Vecchia, C. (2001) Fiber Intake and the Risk of Oral, Pharyngeal and Esophageal Cancer. International Journal of Cancer, 91, 283-287. http://dx.doi.org/10.1002/1097-0215(200002)9999:9999<::AID-IJC1047>3.0.CO;2-I

[28] Otles, S. and Ozgoz, S. (2014) Health Effects of Dietary Fiber. Acta Scientiarum Polonorum. Technologia Alimentaria, 13, 191-202.

[29] Papas, M.A., Giovannucci, E. and Platz, E.A. (2004) Fiber from Fruit and Colorectal Neoplasia. Cancer Epidemiology, Biomarkers and Prevention, 13, 1267-1270.

[30] Vanamala, J., Glagolenko, A., Yang, P., Carroll, R.J., Murphy, M.E., Newman, R.A., et al. (2008) Dietary Fish Oil and Pectin Enhance Colonocyte Apoptosis in Part through Suppression of PPAR $\delta / \mathrm{PGE}_{2}$ and Elevation of PGE 3 . Carcinogenesis, 29, 790-796. http://dx.doi.org/10.1093/carcin/bgm256

[31] Spurling, C.C., Suhl, J.A., Boucher, N., Nelson, C.E., Rosenberg, D.W. and Giardina, C. (2008) The Short Chain Fatty Acid Butyrate Induces Promoter Demethylation and Reactivation of RAR $\beta 2$ in Colon Cancer Cells. Nutrition and Cancer, 60, 692-702. http://dx.doi.org/10.1080/01635580802008278

[32] Bidoli, E., Pelucchi, C., Polesel, J., Negri, E., Barzan, L., Franchin, G., Franceschi, S., Serraino, D., De Paoli, P., La Vecchia, C. and Talamini, R. (2013) Fiber Intake and Risk of Nasopharyngeal Carcinoma: A Case-Control Study. Nutrition and Cancer, 65, 1157-1163. http://dx.doi.org/10.1080/01635581.2013.828088

[33] Daniel, C.R., Park, Y., Chow, W.H., Graubard, B.I., Hollenbeck, A.R. and Sinha, R. (2013) Intake of Fiber and FiberRich Plant Foods Is Associated with a Lower Risk of Renal Cell Carcinoma in a Large US Cohort. The American Journal of Clinical Nutrition, 97, 1036-1043. http://dx.doi.org/10.3945/ajcn.112.045351

[34] Goodman, M.T., Wilkens, L.R., Hankin, J.H., Lyu, L.C., Wu, A.H. and Kolonel, L.N. (1997) Association of Soy and Fiber Consumption with the Risk of Endometrial Cancer. American Journal of Epidemiology, 146, 294-306. http://dx.doi.org/10.1093/oxfordjournals.aje.a009270

[35] Jacobs, L.R. (1986) Relationship between Dietary Fiber and Cancer: Metabolic, Physiologic, and Cellular Mechanisms. Experimental Biology and Medicine, 183, 299-310. http://dx.doi.org/10.3181/00379727-183-42423

[36] Jacobs, L.R. (1986) Modification of Experimental Colon Carcinogenesis by Dietary Fibers. Advances in Experimental Medicine and Biology, 206, 105-118.

[37] Madar, Z., Gurevich, P., Ben-Hur, H., Ben-Arie, A., Berman, V., Sandler, B., et al. (1998) Effects of Dietary Fiber on the Rat Intestinal Mucosa Exposed to Low Doses of a Carcinogen. Anticancer Research, 18, 3521-3526. 
[38] Gonçalves, P. and Martel, F. (2013) Butyrate and Colorectal Cancer: The Role of Butyrate Transport. Current Drug Metabolism, 14, 994-1008. http://dx.doi.org/10.2174/1389200211314090006

[39] Kritchevsky, D. (1997) Dietary Fibre and Cancer. European Journal of Cancer Prevention, 6, 435-441. http://dx.doi.org/10.1097/00008469-199710000-00004

[40] Cappellani, A., Zanghi, A., Di Vita, M., Cavallaro, A., Piccolo, G., Veroux, P., et al. (2013) Strong Correlation between Diet and Development of Colorectal Cancer. Frontiers in Bioscience, 18, 190-198. http://dx.doi.org/10.2741/4095

[41] Ferguson, L.R., Roberton, A.M., Watson, M.E., Kestell, P. and Harris, P.J. (1993) The Adsorption of a Range of Dietary Carcinogens by $\alpha$-Cellulose, a Model Insoluble Dietary Fiber. Mutation Research, 319, 257-266. http://dx.doi.org/10.1016/0165-1218(93)90013-4

[42] Kaczmarczyk, M.M., Miller, M.J. and Freund, G.G. (2012) The Health Benefits of Dietary Fiber: Beyond the Usual Suspects of Type 2 Diabetes Mellitus, Cardiovascular Disease and Colon Cancer. Metabolism-Clinical and Experimental, 61, 1058-1066. http://dx.doi.org/10.1016/j.metabol.2012.01.017

[43] Fiorucci, S., Cipriani, S., Mencarelli, A., Renga, B., Distrutti, E. and Baldelli, F. (2010) Counter-Regulatory Role of Bile Acid Activated Receptors in Immunity and Inflammation. Current Molecular Medicine, 10, 579-595.

[44] Floch, M.H., Wolfman, M. and Doyle, R. (1980) Fiber and Gastrointestinal Microecology. Journal of Clinical Gastroenterology, 2, 175-184. http://dx.doi.org/10.1097/00004836-198006000-00014

[45] Kay, R.M. (1982) Dietary Fiber. Journal of Lipid Research, 23, 221-242.

[46] Cheah, P.Y. and Bernstein, H. (1990) Colon Cancer and Dietary Fiber: Cellulose Inhibits the DNA-Damaging Ability of Bile Acids. Nutrition and Cancer, 13, 51-57. http://dx.doi.org/10.1080/01635589009514044

[47] Ajouz, H., Mukherji, D. and Shamseddine, A. (2014) Secondary Bile Acids: An Underrecognized Cause of Colon Cancer. World Journal of Surgical Oncology, 12, 164. http://dx.doi.org/10.1186/1477-7819-12-164

[48] Hofmann, A.F. and Rods, A.A. (1984) Physicochemical Properties of Bile Acids and Their Relationship to Biological Properties: An Overview of the Problem. Journal of Lipid Research, 25, 1477-1489.

[49] Degirolamo, C., Modica, S., Palasciano, G. and Moschetta, A. (2011) Bile Acids and Colon Cancer: Solving the Puzzle with Nuclear Receptors. Trends in Molecular Medicine, 17, 564-572. http://dx.doi.org/10.1016/j.molmed.2011.05.010

[50] Sloan, D.A., Fleiszer, D.M., Richards, G.K., Murray, D. and Brown, R.A. (1993) The Effect of the Fiber Components Cellulose and Lignin on Experimental Colon Neoplasia. Journal of Surgical Oncology, 52, 77-82. http://dx.doi.org/10.1002/jso.2930520204

[51] Pelucchi, C., La Vecchia, C., Chatenoud, L., Negri, E., Conti, E., Montella, M., Calza, S., Dal Maso, L. and Franceschi, S. (2001) Dietary Fibres and Ovarian Cancer Risk. European Journal of Cancer, 37, 2235-2239. http://dx.doi.org/10.1016/S0959-8049(01)00291-X

[52] La Vecchia, C., Ferraroni, M., Franceschi, S., Mezzetti, M., Decarli, A. and Negri, E. (1997) Fibers and Breast Cancer Risk. Nutrition and Cancer, 28, 264-269. http://dx.doi.org/10.1080/01635589709514586

[53] Lee, S., Monnappa, A.K. and Mitchell, R.J. (2012) Biological Activities of Lignin Hydrolysate-Related Compounds. BMB Reports, 45, 265-274. http://dx.doi.org/10.5483/BMBRep.2012.45.5.265

[54] Lu, F.J., Chu, L.H. and Gau, R.J. (1998) Free Radical-Scavenging Properties of Lignin. Nutrition and Cancer, 30, 3138. http://dx.doi.org/10.1080/01635589809514637

[55] Ferguson, L.R. and Harris, P.J. (1996) Studies on the Role of Specific Dietary Fibres in Protection against Colorectal Cancer. Mutation Research, 350, 173-184. http://dx.doi.org/10.1016/0027-5107(95)00105-0

[56] Freeman, H.J. (1979) Dietary Fibre and Colonic Neoplasia. Canadian Medical Association Journal, 121, 291-296.

[57] McPherson-Kay, R. (1987) Fiber, Stool Bulk, and Bile Acid Output: Implications for Colon Cancer Risk. Preventive Medicine, 16, 540-544. http://dx.doi.org/10.1016/0091-7435(87)90069-7

[58] Adlercreutz, H. (1990) Western Diet and Western Diseases: Some Hormonal and Biochemical Mechanisms and Associations. Scandinavian Journal of Clinical and Laboratory Investigation. Supplementum, 50, 3-23. http://dx.doi.org/10.3109/00365519009085798

[59] Reddy, B.S., Maeura, Y. and Wayman, M. (1983) Effect of Dietary Corn Bran and Autohydrolyzed Lignin on 3,2'Dimethyl-4-Aminobiphenyl-Induced Intestinal Carcinogenesis in Male F344 Rats. Journal of the National Cancer Institute, 71, 419-423.

[60] Adlercreutz, H., Honjo, H., Higashi, A., Fotsis, T., Hamalainen, E., Hasegawa, T. and Okada, H. (1991) Urinary Excretion of Lignans and Isoflavonoid Phytoestrogens in Japanese Men and Women Consuming a Traditional Japanese Diet. The American Journal of Clinical Nutrition, 54, 1093-1100.

[61] Buck, K., Zaineddin, A.K., Vrieling, A., Heinz, J., Linseisen, J., Flesch-Janys, D. and Chang-Claude, J. (2011) Esti- 
mated Enterolignans, Lignan-Rich Foods, and Fibre in Relation to Survival after Postmenopausal Breast Cancer. British Journal of Cancer, 105, 1151-1157. http://dx.doi.org/10.1038/bjc.2011.374

[62] Saarinen, N.M., Wärri, A., Airio, M., Smeds, A. and Mäkelä, S. (2007) Role of Dietary Lignans in the Reduction of Breast Cancer Risk. Molecular Nutrition and Food Research, 51, 857-866. http://dx.doi.org/10.1002/mnfr.200600240

[63] Adlercreutz, H., Mousavi, Y., Clark, J., Höckerstedt, K., Hämäläinen, E., Wähälä, K., Mäkelä, T. and Hase, T. (1992) Dietary Phytoestrogens and Cancer: In Vitro and in Vivo Studies. The Journal of Steroid Biochemistry and Molecular Biology, 41, 331-337. http://dx.doi.org/10.1016/0960-0760(92)90359-Q

[64] Horn-Ross, P.L., Hoggatt, K.J. and Lee, M.M. (2002) Phytoestrogens and Thyroid Cancer Risk: The San Francisco Bay Area Thyroid Cancer Study. Cancer Epidemiology, Biomarkers and Prevention, 11, 43-49.

[65] Leclere, L., Custem, P.V. and Michiels, C. (2013) Anti-Cancer Activities of pH- or Heat-Modified Pectin. Frontiers in Pharmacology, 4, 128. http://dx.doi.org/10.3389/fphar.2013.00128

[66] Barry, K.A., Wojcicki, B.J., Middelbos, I.S., Vester, B.M., Swanson, K.S. and Fahey Jr., G.C. (2010) Dietary Cellulose, Fructooligosaccharides, and Pectin Modify Fecal Protein Catabolites and Microbial Populations in Adult Cats. Journal of Animal Science, 88, 2978-2987. http://dx.doi.org/10.2527/jas.2009-2464

[67] Attari, F., Sephehri, H., Delphi, L. and Golliaei, B. (2009) Apoptotic and Necrotic Effects of Pectic Acid on Rat Pituitary GH3/B6 Tumor Cells. Iranian Biomedical Journal, 13, 229-236.

[68] Cho, Y., Turner, N.D., Davidson, L.A., Chapkin, R.S., Carroll, R.J. and Lupton, J.R. (2012) A Chemoprotective Fish Oil/Pectin Diet Enhances Apoptosis via Bcl-2 Promoter Methylation in Rat Azoxymethane-Induced Carcinomas. Experimental Biology and Medicine (Maywood, N.J.), 237, 1387-1393. http://dx.doi.org/10.1258/ebm.2012.012244

[69] Hao, M., Yuan, X., Cheng, H., Xue, H., Zhang, T., Zhou, Y. and Tai, G. (2013) Comparative Studies on the AntiTumor Activities of High Temperature- and pH-Modified Citrus Pectins. Food and Function, 4, 960-971. http://dx.doi.org/10.1039/c3fo30350k

[70] Liu, Y., Colditz, G.A., Cotterchio, M., Boucher, B.A. and Kreiger, N. (2014) Adolescent Dietary Fiber, Vegetable Fat, Vegetable Protein, and Nut Intakes and Breast Cancer Risk. Breast Cancer Research and Treatment, 145, 461-470. http://dx.doi.org/10.1007/s10549-014-2953-3

[71] Hsu, D.K., Chen, H.Y. and Liu, F.T. (2009) Galectin-3 Regulates T-Cell Functions. Immunological Reviews, 230, 114127. http://dx.doi.org/10.1111/j.1600-065X.2009.00798.x

[72] Nagina-Makker, P., Hogan, V., Honjo, Y., Baccarini, S., Tait, L., Bresalier, R. and Raz, A. (2002) Inhibition of Human Cancer Cell Growth and Metastasis in Nude Mice by Oral Intake of Modified Citrus Pectin. Journal of the National Cancer Institute, 94, 1854-1862. http://dx.doi.org/10.1093/jnci/94.24.1854

[73] Zeng, H. and Briske-Anderson, M. (2005) Prolonged Butyrate Treatment Inhibits the Migration and Invasion Potential of HT1080 Tumor Cells. Journal of Nutrition, 135, 291-295.

[74] Elangovan, S., Pathania, R., Ramchandran, S., Ananth, S., Padia, R.N., Lan, L., et al. (2014) The Niacin/Butyrate Receptor GPR109A Suppresses Mammary Tumorigenesis by Inhibiting Cell Survival. Cancer Research, 74, 1166-1178. http://dx.doi.org/10.1158/0008-5472.CAN-13-1451

[75] Inohara, H. and Raz, A. (1994) Effects of Natural Complex Carbohydrate (Citrus Pectin) on Murine Melanoma Cell Properties Related to Galectin-3 Functions. Glycoconjugate Journal, 11, 527-532. http://dx.doi.org/10.1007/BF00731303

[76] Platt, D. and Raz, A. (1992) Modulation of the Lung Colonization of B16-F1 Melanoma Cells by Citrus Pectin. Journal of the National Cancer Institute, 84, 438-442. http://dx.doi.org/10.1093/jnci/84.6.438

[77] Hague, A., Elder, D.J., Hicks, D.J. and Paraskeva, C. (1995) Apoptosis in Colorectal Tumour Cells: Induction by the Short Chain Fatty Acids Butyrate, Propionate and Acetate and by the Bile Salt Deoxycholate. International Journal of Cancer, 60, 400-406. http://dx.doi.org/10.1002/ijc.2910600322

[78] Xiao, M., Liu, Y.G., Zou, M.C. and Zou, F. (2014) Sodium Butyrate Induces Apoptosis of Human Colon Cancer Cells by Modulating ERK and Sphingosine Kinase 2. Biomedical and Environmental Sciences, 27, 197-203.

[79] Hague, A., Manning, A.M., Hanlon, K.A., Huschtscha, L.I., Hart, D. and Paraskeva, C. (1993) Sodium Butyrate Induces Apoptosis in Human Colonic Tumour Cell Lines in a p53-Independent Pathway: Implications for the Possible Role of Dietary Fibre in the Prevention of Large-Bowel Cancer. International Journal of Cancer, 55, 498-505. http://dx.doi.org/10.1002/ijc.2910550329

[80] Roberfroid, M.B. (2005) Introducing Inulin-Type Fructans. British Journal of Nutrition, 93, S13-S25. http://dx.doi.org/10.1079/BJN20041350

[81] Pasqualetti, V., Altomare, A., Guarino, M.P., Locato, V., Cocca, S., Cimini, S., Palma, R., Alloni, R., De Gara, L. and Cicala, M. (2014) Antioxidant Activity of Inulin and Its Role in the Prevention of Human Colonic Muscle Cell Impairment Induced by Lipopolysaccharide Mucosal Exposure. PLoS ONE, 9, e98031.

http://dx.doi.org/10.1371/journal.pone.0098031 
[82] Burns, A.J. and Rowland, I.R. (2000) Anti-Carcinogenicity of Probiotics and Prebiotics. Current Issues in Intestinal Microbiology, 1, 13-24.

[83] Taper, H.S. and Roberfroid, M.B. (2000) Inhibitory Effect of Dietary Inulin or Oligofructose on the Development of Cancer Metastases. Anticancer Research, 20, 4291-4294. 
Scientific Research Publishing (SCIRP) is one of the largest Open Access journal publishers. It is currently publishing more than 200 open access, online, peer-reviewed journals covering a wide range of academic disciplines. SCIRP serves the worldwide academic communities and contributes to the progress and application of science with its publication.

Other selected journals from SCIRP are listed as below. Submit your manuscript to us via either submit@scirp.org or Online Submission Portal.
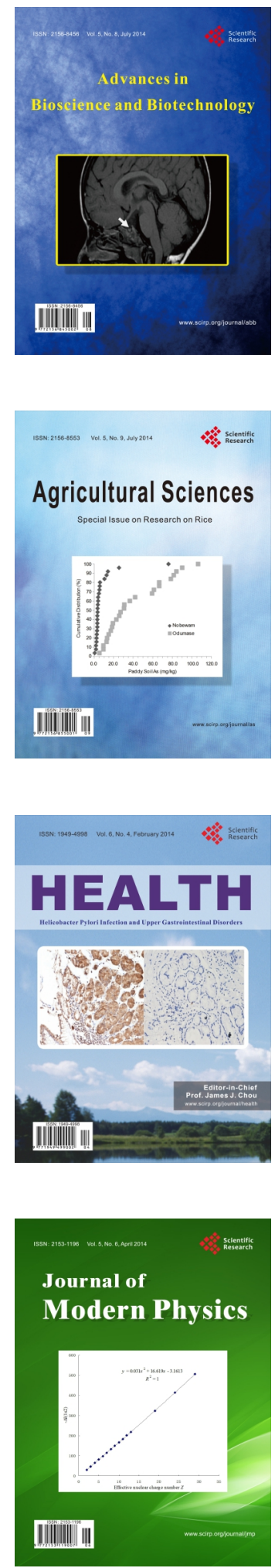
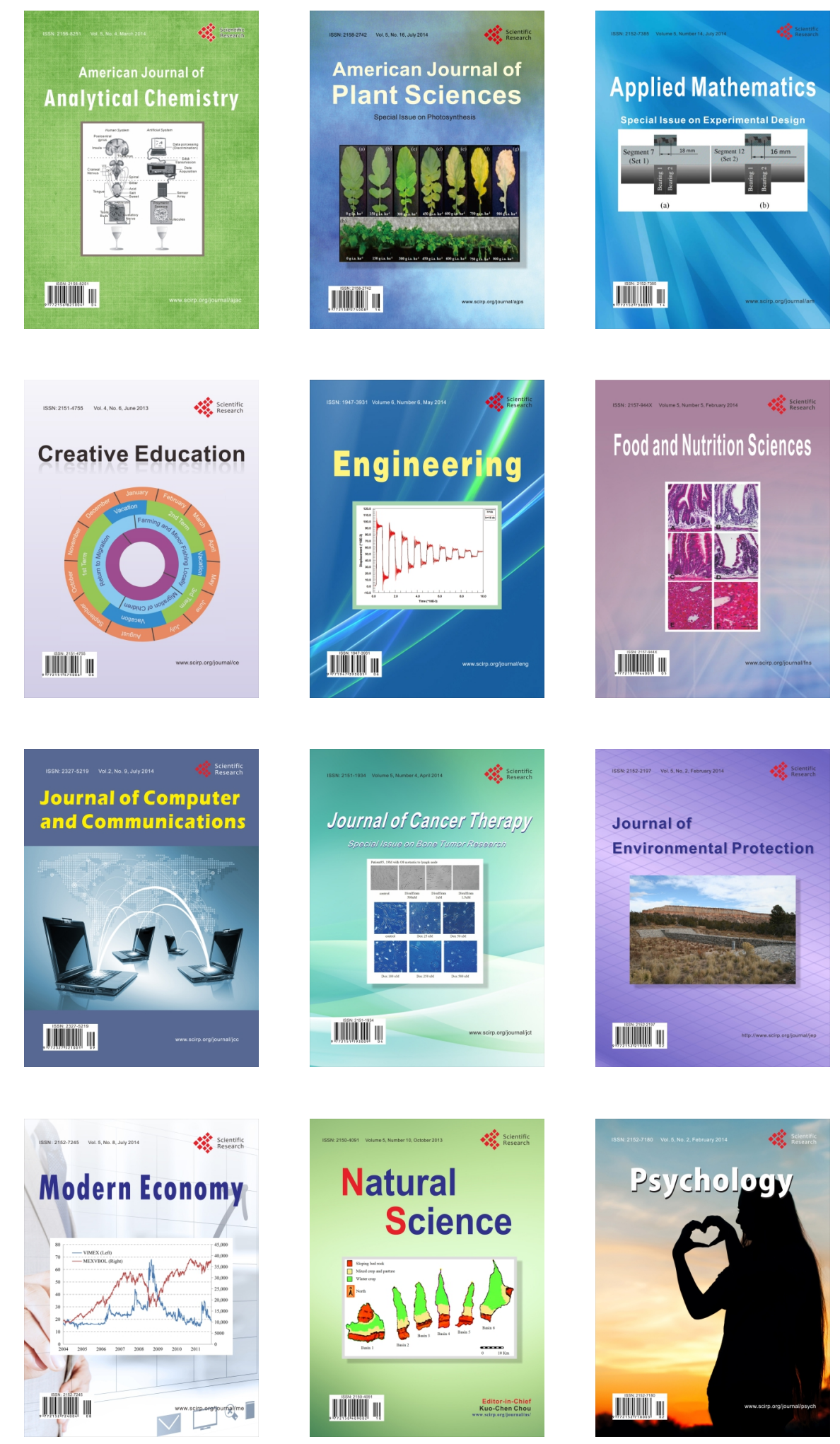